\title{
Effect of cosurfactant on the supramolecular structure and physicochemical properties of non-ionic biocompatible microemulsions
}

\author{
Kélia Xavier Resende, Marcos Antonio Corrêa, Anselmo Gomes de Oliveira, \\ Maria Virgínia Scarpa*
}

Faculdade de Ciências Farmacêuticas, Universidade Estadual Paulista Júlio de Mesquita Filho

\footnotetext{
${ }^{*}$ Correspondence:

M.V. Scarpa

Departamento de Fármacos e

Medicamentos.

Faculdade de Ciências Farmacêuticas

- UNESP

Rodovia Araraquara-Jaú km 01

14801-902 - Araraquara - SP, Brasil

E-mail: scarpamv@fffar.unesp.br
}

\begin{abstract}
Microemulsions are transparent, homogeneous and thermodynamically stable systems, formed spontaneously under a specific set of experimental conditions from mixtures of water and oil phases stabilized by a surfactant or a mixture of surfactant and cosurfactant. These systems exhibit some unique properties that make them particularly interesting as delivery systems, as much for the oral as for the topical route. In the present work, we have studied the domain of existence of non-ionic microemulsion systems within pseudo-ternary phase diagrams. The results show a large area of microemulsion domain for $\mathrm{O} / \mathrm{W}$ and $\mathrm{W} / \mathrm{O}$ microemulsions. Depending on the proportion of components the apparent viscosity of the systems varied significantly. We have found that the presence of ethanol as cosurfactant affects the physical properties particularly the apparent viscosity and relative density. Analysis of the data indicated that the studied systems behave as non-Newtonian pseudoplastic shear-thinning fluids appropriated for pharmaceutical and cosmetic applications.
\end{abstract}

\section{Uniterms}

- Microemulsion

- Surfactant

- Pseudo-ternary phase diagram

- Physicochemical properties

- Drug carrier

\section{INTRODUCTION}

Microemulsions (MEs) are isotropic, transparent or translucent and thermodynamically stable systems formed spontaneously under a specified set of experimental conditions by the mixture of water and oil, stabilized with surfactants and cosurfactants (Overbeek et al., 1984; Kumar, Mittal, 1999; Constantinides et al., 1994; Oliveira et al., 1997; Dalmora, Oliveira, 1999; Dalmora et al., 2001; Oliveira et al., 2003; Oliveira et al., 2004). MEs have a number of special properties and have frequently been studied as drug delivery systems for transdermal applications. It is well-established that microemulsions can increase the solubility of lipophilic drugs in aqueous medium and improve drug stability (Oliveira et al., 2004; Correa et al., 2005; Formariz et al., 2006). Thus, microemulsions are interesting vehicles for pharmaceutical and cosmetic formulations (Dalmora et al., 2001; Formariz et al., 2004; Oliveira et al., 2004).

Microemulsion can be understood as micronized forms of traditional emulsions, the dimension of the disperse phase being on the nanometer scale. The thermodynamic stability of MEs arises from their extremely low interfacial tension, which allows the spontaneous formation and the preparation methods are extremely simple (Rosano, 1974; Cera 2001; Oliveira, Scarpa, 2001; Corrêa et al., 2005; 
Formariz et al., 2006). Since in microemulsification the formation of the very small droplets leads to a great increase in interfacial area the free energy also increases substantially (Overbeek et al., 1984; Bourrel, Schechter, 1988; Kumar, Mittal, 1999). In fact, ME results from a large free energy $(\Delta \mathrm{G})$ of surfactant's adsorption components combined with a low interfacial tension. The Helmholtz's free energy changes for any process, which alters the interfacial area at constant volume and temperature can be given by the equation (Morrison, Ross, 2002):

$$
\Delta \mathrm{G}=\gamma i \mathrm{x} \Delta \mathrm{S}-\mathrm{W}^{\mathrm{des}}-\Delta n
$$

where, $\gamma i$ is the interfacial free energy, $\Delta \mathrm{S}$ is the change of interfacial area, $\mathrm{W}^{\text {des }}$ is the work of desorption $(\mathrm{mJ} / \mathrm{mole})$, and $\Delta n$ is the number of moles desorbed.

In this process, the desorption work is the result of some parameters such as changes of entropy and molecular interactions between the constituents of the interfacial film. If the work of desorption is sufficiently large and the interfacial free energy is sufficiently small, $\mathrm{dG} / \mathrm{dS}<0$, the interfacial area increases spontaneously (Morrison, Ross, 2002).

However, surfactants in general can not reduce the interfacial free energy sufficiently to increase spontaneously the interfacial area. Therefore, in many cases the addition of a cosurfactant is necessary to produce thermodynamically stable systems. In these cases, the ratio between surfactant and cosurfactant is extremely important to stabilize thermodynamically the system (Corrêa, 1996; Oliveira, Scarpa, 2001; Oliveira et al., 2004). The length of cosurfactant alkyl chain, the composition of the oil phase, and the ratio of the surfactant in the formulation directly influence the formation and the properties of microemulsions (Rosano, 1974; Corrêa, 1996; Reilgaard, 2002). Moreover, depending on the composition different microstructures can be formed, such as $\mathrm{O} / \mathrm{W}$ and $\mathrm{W} / \mathrm{O} \mathrm{ME}$ and, bicontinuous structures (Mittal, Lindman, 1984; Bourrel, Schechter, 1988; Lawrence, Rees, 2000; Nagarajan, Ruckenstein, 2000), which can strongly influence the drug release and make phase diagram knowledge extremely important (Dalmora, Oliveira, 1999; Dalmora et al., 2001; Corrêa et al., 2005, Formariz, 2007).

Pharmaceutical and cosmetic products need adjusted viscosity and adequate rheological behavior for topical administration in order to improve drug release (Hadgraft, 2001; Matsumoto, Shermann, 1969; Mollet, Grubenmann, 2001; Wester, Maibach, 1996. Besides, thixotropic properties are relevant for these applications because after spreading, the product must have adequate consistency on the skin for release purposes (Matsumoto, Shermann, 1969; Mollet, Grubenmann, 2001).
In the present study the effects of the cosurfactant ethanol on the formation of the internal microstructure of systems (obtained by mixing water, dibutyl adipate and Procetyl AWS ${ }^{\circledR}$ ) and some physicochemical properties of microemulsions were investigated.

\section{MATERIAL AND METHODS}

\section{Materials}

Polyoxypropylene (5) Poloxyethylene (20) Cetyl Ether (PPG-5), CAS 9087-53-0 (Procethyl AWS ${ }^{\circledR}$, Croda Inc., U.S.A.), n-dibutyl adipate, CAS 105-99-7 (Polymol $\mathrm{ADB}^{\circledR}$, Polytecnno, Brasil), absolute ethanol (Merck S.A., Brazil). Water was purified using a Milli Q Plus water purification system (Millipore) which resistivity was 18.2 MW-cm. All other solvents and chemicals were analytical grade.

\section{Methods}

Microemulsion preparation: To selected weights of the surfactant PPG-5, an adequate weight of ethanol and water were added. This addition sequence enabled the "dissolution" of the surfactant with gentle stirring. The mixture was left for $10 \mathrm{~min}$ in a temperature-controlled room at $25 \pm 0.1^{\circ} \mathrm{C}$.

Phase diagram determination: An adequate weight of ethanol was added to a suitable weight of PPG-5. Dibutyl adipate (O) was then added to semisolid PPG-5/Ethanol (8:2) (S) mixture. S/O weight ratios from 1:9 to 9:1 were used to obtain the phase diagram. The composition of each experimental point was described in the phase diagrams of Figure 1. To semisolid mixture containing $\mathbf{S}$ and $\mathbf{O}(1.0 \mathrm{~g})$ constantly stirred the water phase $(\mathbf{W})$ was slowly added with a precision burette. The transitions from semisolid mixture to optically clear liquid microemulsion, from liquid microemulsion to gel microemulsion, from liquid microemulsion to semi-transparent emulsion and to opaque emulsion or separated phases were sharp and reproducible to within $0.05 \mathrm{~mL}$ of $\mathbf{W}$. A similar procedure was carried out, using only PPG-5 as surfactant. The titrations were carried out in a controlled temperature room at $25 \pm 0.1^{\circ} \mathrm{C}$.

Refractive index: The assays were carried out in a $25 \pm 0.1^{\circ} \mathrm{C}$ temperature controlled chamber using Abbe refratometer, Carl Zeiss Jena, previously calibrated with bidistilled and deionized water.

Relative density: Measurements were carried out at 25 $\pm 0.1^{\circ} \mathrm{C}$ with a picnometer method using double-distilled and deionized water as reference. The ratio of the mass to the volume of the preparation gives the relative density: 


$$
\rho=\rho_{v}\left(m_{3}-m_{1}\right) /\left(m_{2}-m_{1}\right)
$$

where $\boldsymbol{m}_{1}$ is the mass of the empty pycnometer, $\boldsymbol{m}_{2}$ the mass of pycnometer plus water and $\boldsymbol{m}_{3}$ is the mass of pycnometer plus ME sample.

Rheological study: Rheological profiles and apparent viscosities of microemulsions with and without cosurfactant were determined using a digital rotacional rheometer coupled with a cup and bob measuring device Selecta model Visco star-L P. The rheological measurements were performed for both, rising and falling shear-rates. Apparent viscosity was measured at various shear-rates and $25 \pm 0.1{ }^{\circ} \mathrm{C}$. Experiments were carried out in triplicate for all samples.

\section{RESULTS}

The phase diagrams of the systems are represented in Figure 1. In Figure 1, system A, shows the microstructures obtained in the absence of cosurfactant. The results in the Figure 1B represent the systems obtained from the mixture of water, dibutyl adipate and surfactant composed of PPG5/ethanol 8:2. In the diagrams, the limits of the regions of liquid microemulsion (LME), gel microemulsion (GME), semi-transparent emulsion (ST), opaque emulsions (OE), and phase separation (PS) regions are indicated.

In the phase diagram of the system A, without cosurfactant, a broad region can be seen in which liquid microemulsion exist with predominance up to $72 \%$ of oil phase. Gel microemulsion region occurs within the aqueous phase limits of 35 and $50 \%$ and it is followed by a semitransparent phase (ST) up to $60 \%$ of aqueous phase. In Figure 1 , system A, the ST microstructure represents a region of transition between microstructure of liquid microemulsions and opaque emulsions. In fact, the semi-transparent aspect of this system reveals the presence of droplets with dimensions between microemulsions and normal opaque emulsions. The presence of cosurfactant (Figure 1, system B), provokes an increase in the domain of liquid microemulsions, the extending the limits to about $88 \%$ of oil phase. The minimum content ratio required of surfactant to obtain gel microemulsions was approximately $30 \%$ for the system containing cosurfactant (Figure 1, system B) and about 33\% without cosurfactant (Figure 1, system A), that can incorporate $50-55 \%$ of aqueous phase. Liquid microemulsions were obtained with more than $16 \%$ of surfactant in the system with cosurfactant and $30 \%$ without cosurfactant. Thus, it was observed that cosurfactant increases the domains for both gel and liquid microemulsions. However, the microstructure cannot be inferred only from phase diagrams since phase behavior patterns of several organized assemblies as micelles and microemulsions are qualitatively similar. In the present work, the microstructures of the phases formed have not been investigated by independent techniques, e.g., X-ray scattering. Therefore, the data of the phase diagram showed in the Figure 1 and discussed above was stated only as LME.

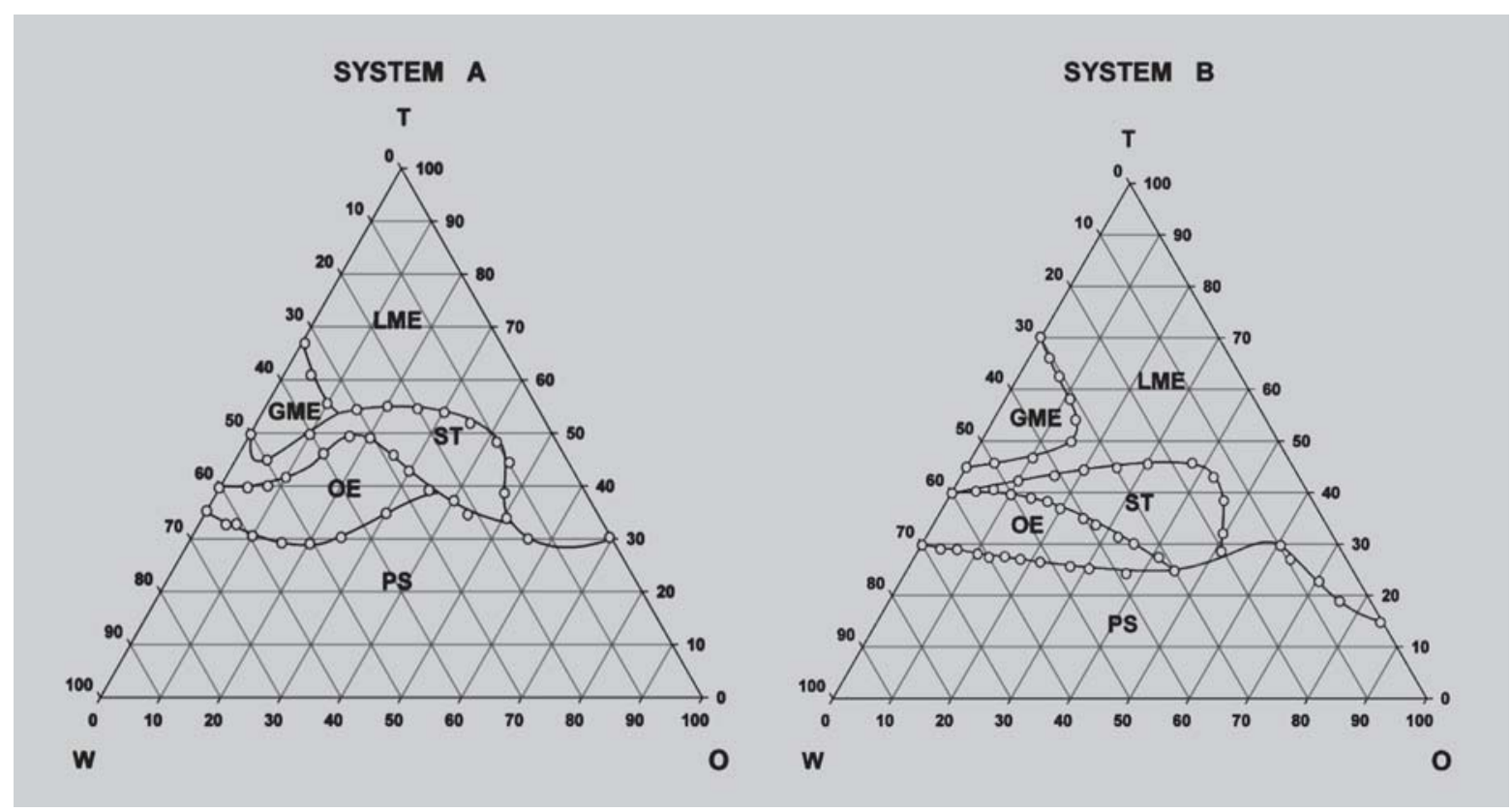

FIGURE 1 - Pseudo-ternary phase diagram obtained of microemulsions. (System A) Whithout Cosurfactant (System B) Whith cosurfactant. Key: (LME) Liquid microemulsions; (GME) Gel microemulsions; (OE) Opaque emulsions; (ST) Semi-transparent emulsions; (PS) Phase separation; (O) Experimental points; Temperature $25 \pm 0.1^{\circ} \mathrm{C}$. 
TABLE I - Composition of the microemulsions used in this study.

\begin{tabular}{lcccc}
\hline ME & Water (\%) & n-dibutyl adipate (\%) & PPG-5 (\%) & PPG-5/ethanol (8:2) (\%) \\
\hline $\mathrm{A}_{1}$ & 35 & 5 & 60 & - \\
$\mathrm{B}_{1}$ & 35 & 5 & - & 60 \\
\hline
\end{tabular}

Mixtures containing predominantly the aqueous phase relative to the oil phase and with a high viscosity, desirable for cosmetic application, were prepared for these experiments. The regions selected in the phase diagram contained $35 \%$ water, $5 \%$ dibutyl adipate and $60 \%$ surfactant or surfactant/cosurfactant mixture and these were used for physicochemical determinations (Table I).

The measured refractive indices (RI) for microemulsions with and without cosurfactant were 1.416 and 1.423 , respectively. These values are greater than RI of distilled water (1.333), and ethanol (1.359) and smaller than PPG-5 (1.456) and n-dibutyl adipate (1.436) but are related to internal microstructural organization of the systems. In fact, this behavior is consistent with the microdroplets organization of the internal phase of the microemulsion, which refracts more light than the homogeneous distilled water. Besides, the composition of the microdroplets containing some organic constituents with refractive index greater than the values of water also contributes to this increase of the RI in the organized structure of the microemulsion.

The relative density $(\delta)$ showed a small increase caused by the presence of ethanol. The values obtained for $\delta$ were 1.021 for the microemulsion in the absence of cosurfactant and 1.111 when the cosurfactant was present, demonstrating the negligible influence of this cosurfactant on this parameter. In fact, the content of ethanol $(\delta=0.792)$ in the total composition of formulation was only $12 \%$ versus $35 \%$ of the water $(\delta=0.997)$ proportion, $48 \%$ of PPG-5 $(\delta=1.04)$, and $5 \%$ of n-butyl adipate $(\delta=0.962)$.

The apparent viscosity determined with the rotating viscometer at $60 \mathrm{rpm}$ was $983 \mathrm{mPa} . \mathrm{s}$ for microemulsion without cosurfactant and $358 \mathrm{mPa}$.s when the cosurfactant was present. This decrease of the apparent viscosity demonstrated that the cosurfactant strongly influenced the formation of the internal phase structure of the microemulsion. It was verified that the viscosity is independent of the time of shear at constant speed, showing an absence of thixotropic properties for both systems.

The rheological profiles of microemulsions $\mathrm{A}_{1}$ and $\mathrm{B}_{1}$ are shown in Figure 2.

For both, ME cosurfactant-free and ME with cosurfactant, an intense dependence of the viscosity on the shear tension was observed. Except at very low speeds where it was low and constant, viscosity increased very quickly, reaching a plateau at high speed. The maximum value obtained for viscosity in the absence of cosurfactant was $983 \mathrm{mPa}$.s and in its presence, $358 \mathrm{mPa}$.s. It is
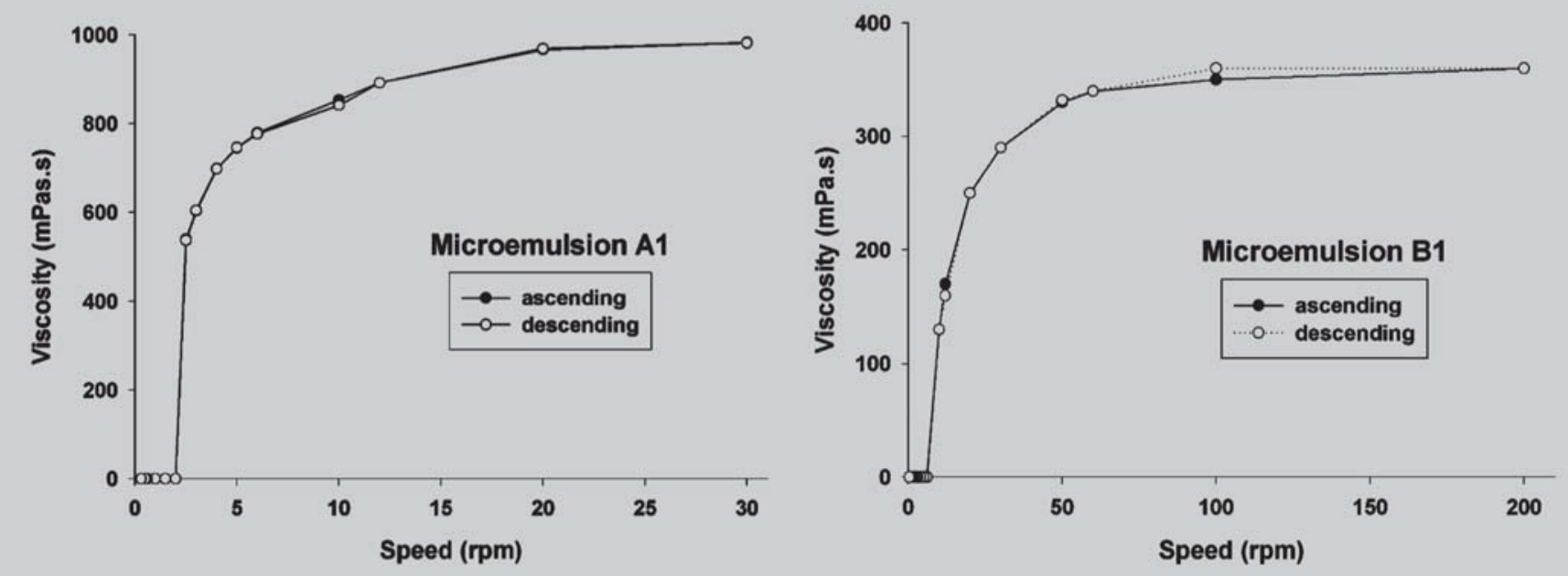

FIGURE 2 - Rheological behavior of ME stabilized with PPG-5. (See table 1 for formulations details). Key: (A1) ME cosurfactant-free (B1) ME with cosurfactant. Temperature: $25 \pm 0.1^{\circ} \mathrm{C}$. 
interesting to note that for all formulations, ascending and descending curves overlapped, showing no hysteresis area and demonstrating the absence of thixotropy. The microemulsions without cosurfactant (A1), as well as reaching much higher viscosities in comparation with cosurfactant (B1), also reached its maximum viscosity at much lower speed.

These curves revealed that the ME systems exhibited a non-linear relationship between the viscosity and shear rate showing non-Newtonian flow characteristic. In this case, the viscosity may be termed "apparent viscosity" and a power-law model can be used to describe the flow characteristics of the MEs. Thus, the flow behavior could be described by the expression (Chen and Dai, 1984):

$$
\tau=\mathrm{k} \cdot(\gamma)^{\mathrm{n}}
$$

where $\mathbf{t}$ is the shear stress in $\mathrm{Pa}, \mathbf{k}$ is a constant parameter related to the viscosity (consistency index) and $\mathbf{n}$ is the flow behavior index. In this model $\mathbf{n}>\mathbf{1}$ representing a dilatant fluid; $\mathbf{n}<\mathbf{1}$ representing a pseudoplastic fluid and Newtonian fluids have $\mathbf{n}=\mathbf{1}$.

Table 2 gives the values of $\mathbf{k}$ and $\mathbf{n}$ obtained for the two microemulsions with and without cosurfactant. In this Table $\mathrm{r}^{2}$ represents the regression coefficient.

TABLE II - Effect of the compositions of the ME on their flow behavior and consistency.

\begin{tabular}{lccc}
\hline ME & $\mathrm{n}$ & $\boldsymbol{k}($ Pa.s $)$ & $\mathrm{r}^{2}$ \\
\hline A1 & 0.72 & 0.95 & 0.974 \\
B1 & 0.67 & 0.33 & 0.957 \\
\hline
\end{tabular}

See Table 1 for formulation details

\section{DISCUSSION}

Ethanol is a widely used alcohol in pharmaceutical and cosmetic formulations and was chosen for the present work due to its low topical toxicity, to its property to combine easily in various proportions with surfactants to form mixtures with high dissolving power and due to its good property as cosurfactant for ME systems (Oliveira et al., 1997; 2003).

The data in the pseudo-ternary phase diagram (Figure 1) show that it is possible to add a great volume of oil phase to a limited volume of aqueous phase and still maintain the thermodynamic stability of the systems. The clear and translucent regions are shown in the phase diagram as ME system domain in the Figure 1. Analysis of the regions of the phase diagram (Figure 1) shows that distinct transition from separated phases to opaque emulsion, gel clear microemulsion to liquid clear microemulsion and clear microemulsion to semitransparent liquid phase could be observed. Depending on the oil phase contents, it was verified that about $30-55 \%$ of aqueous phase was necessary to form GME phases.

The flow curves (Figure 2) revealed that the ME systems showed a nonlinear relationship between the shear stress and shear rate exhibiting non-Newtonian flow. In this case the "apparent viscosity" was dependent on the shear rate, pressure and temperature and the system behaved as a pseudoplastic fluid.

The data in Figure 2 show that the addition of cosurfactant favored an enlargement of the domains of microemulsions, compared with the system without cosurfactant. This tendency was also observed in the significant reduction in the minimum surfactant ratio required to obtain clear microemulsions.

The apparent viscosity results, in Figure 2, demonstrate clearly that when the cosurfactant was present the maximum obtained viscosity was lower than in its absence. With cosurfactant the viscosity reached at the maximum value of $358 \mathrm{mPa}$.s, as can be seen in Figure 2 (microemulsion B1). Under the same experimental conditions, the viscosity of microemulsion A1 (without cosurfactant) reached significantly bigger values (about $860 \mathrm{cP}$ ) in the gel microemulsion domain, as can be observed in the phase diagram in Figure 1A.

For explanation the effect of the cosurfactant on the apparent viscosity of the microemulsion, we took into account that the microemulsions described in the present work have a core region surrounded by an interfacial film of surfactant and cosurfactant. The cosurfactant is organized with its $\mathrm{OH}$ group lying among the polar group of surfactant and neighboring water molecules and the hydrocarbon groups lying among the apolar chain of the surfactant. However, all of the alcohol molecules will not resides within interfacial region. A fraction will be distributed between the oil and water phases according to its relative solubility. For instance, ethanol that has a dielectric constant value about 23 will be largely distributed to interfacial and water regions where the local interfacial dielectric constant is about 33 . Thus, when the alcohol mixes with the surfactant-water-oil system, a change in the interactions energy of the oil-water interface is observed. With nonionic surfactant as PPG-5, hydrogen bonding can occur between the surfactant and hydrophilic alcohols as ethanol. On the other hand, the energy of interaction per molecule with water of the alcohol and surfactant is not constant and decreases due to self-association mechanism through intermolecular hydrogen bonding, which reduces 
the ability of the $\mathrm{OH}$ group of the alcohol to form hydrogen bonds with water. Due to these effects, the presence of the ethanol molecules located at oil-water interface of the microemulsion A1, decreases the fluidity of the interfacial film reducing the apparent viscosity of the system.

These rheograms show that the MEs behave as nonNewtonian fluids, with pseudoplastic characteristics without thixotropy, showing that viscosity is independent of shear time. The absence of hysteresis in both systems shows their rapid structural reorganization after shear.

As seen in results of Table 2 , all $\mathbf{n}$ values obtained are less than one, indicating that the microemulsions behave as pseudoplastic shear-thinning fluids. This behavior is related to the orientation of droplets towards the flow, caused by shearing of the system. Microemulsions with similar rheological behaviors were previously studied and suggested as efficient vehicles for drug carriers (Formariz et al., 2006; 2007).

The degree of shear-thinning could be assessed through the $\mathbf{n}$ parameter which decreases as the pseudoplastic characteristic increases. From the data in Table 2, it was found that $\mathbf{n}$ value decreased in the presence of the cosurfactant provoking a decrease in the pseudoplasticity of the system. The values of $\mathbf{k}$ calculated from eq. 1, which represent the consistency index of the systems, were very similar to the experimental data. In fact, when the cosurfactant was added to system ME, it became more mobile on stirring. This is a desirable property in pharmaceutical and cosmetic dispersions such as ME, especially for pseudoplastic systems, because a decrease in the viscosity facilitates not only the administration but also the preparation of the ME.

\section{CONCLUSIONS}

The results of this work show that it is possible to obtain an oil-in-water microemulsion stabilized by PPG-5, mixed or not with cosurfactant. It was demonstrated that the presence of cosurfactant increases the domains viscous, liquid transparent and semi-transparent systems. From the pseudo-ternary phase diagrams it was possible to describe the critical mixtures between the components that provide systems with various microstructures, evidenced by specific viscosities and transparencies. The analysis of the data suggests that the systems under study behave nonNewtonian pseudoplastic shear-thinning fluids. It was conclude that the physicochemical characteristics of the investigated ME system make it a potentially vehicle for drugs-carrier and cosmetic products.

\section{RESUMO}

\section{Efeito de cotensoativo na obtenção e nas proprieda- des físico-químicas de microemulsões não iônicas}

Microemulsões são sistemas transparentes, homogêneos e termodinamicamente estáveis, formados espontaneamente, sob determinadas condições experimentais, a partir de misturas de água e fase oleosa estabilizadas por tensoativo ou por mistura de tensoativo e cotensoativo. Esses sistemas exibem propriedades diferenciadas, as quais os tornam particularmente interessantes como sistemas de liberação, principalmente pelas vias oral e tópica. Nesse trabalho foi estudado o domínio da existência de sistemas microemulsionados não iônicos, através de diagramas de fase pseudo-ternários. Os resultados mostraram uma grande área de domínio para microemulsões $O / A$ e A/O, onde A e O referem-se a água e óleo, respectivamente. Dependendo das proporções dos componentes, a viscosidade aparente dos sistemas variou significantemente. Foi determinado que a presença de etanol como cotensoativo modificou as propriedades fisico-químicas dos sistemas, particularmente da viscosidade aparente e da densidade relativa. A análise dos dados mostrou que o sistema estudado comporta-se como um fluido não-Newtoniano pseudoplástico próprio para aplicações farmacêuticas e cosméticas.

UNITERMOS: Microemulsão. Diagramas de fases pseudo-ternários. Propriedades físico-químicas. Sistema transportador.

\section{ACKNOWLEDGMENTS}

The authors wish to thanks to FAPESP, CNPq, CAPES, and PDC-FCF for financial support.

\section{REFERENCES}

BOURREL, M.; SCHECHTER, R. S. (Eds.). Microemulsions and related systems. Marcel Dekker: New York, 1988. 483p.

CERA, L. F. R. Estudo da interação do diclofenaco sódico com microemulsões lipídicas: formulação e liberação “in vitro". Araraquara, 2001. 145 f. [Dissertação de Mestrado. Faculdade de Ciências Farmacêuticas, Universidade Estadual Paulista "Júlio de Mesquita Filho"]. 
CHEN, Z. Q.; DAI, Z. G. Colloid chemistry. Beijing: Higher Education Press, 1984. 432p.

CONSTANTINIDES, P. P.; SCARLAT, J. P.; LANCASTER, C.; MARCELLO, J.; MARKS, G.; ELLENS, H.; SMITH, P. L. Formulation and intestinal absorption enhancement evaluation of water in oil microemulsions incorporating medium-chain glycerides. Pharm. Res., New York, v.11, p. 1385-1390, 1994.

CORREA, M. A. Incorporação de naproxeno em sistema microemulsionado: liberação in vitro e avaliação biológica. São Paulo,1996. 140 f. [Tese de Doutorado. Faculdade de Ciências Farmacêuticas. Universidade de São Paulo].

CORREA, M. A.; SCARPA, M. V.; FRANZINI, C. M.; OLIVEIRA, A. G. On the incorporation of the non steroidal anti-inflammatory naproxen into cationic $\mathrm{O} / \mathrm{W}$ microemulsions. Colloids Surfaces B., Amsterdam, v.43, p.108-114, 2005.

DALMORA, M. E. A.; DALMORA, S. L.; OLIVEIRA, A. $\mathrm{G}$. Inclusion complex of piroxicam with $\beta$-cyclodextrin and incorporation in cationic microemulsion. In vitro drug release and in vivo topical anti-inflammatory effect. Int. J. Pharm., Amsterdam, v.222, p.45-55, 2001.

DALMORA, M. E. A.; OLIVEIRA, A. G. Inclusion complex of piroxicam with b-cyclodextrin and incorporation in hexadecyltrimethylammonium bromide based microemulsion. Int. J. Pharm., Amsterdam, v.184, p.157$164,1999$.

FORMARIZ, T. P.; SARMENTO, V. H. V.; SILVAJUNIOR, A. A.; SCARPA, M. V.; SANTILLI, C. V.; OLIVEIRA, A. G. Doxorubicin biocompatible O/W microemulsion stabilized by mixed surfactant containing soya phosphatidylcholine. Colloids Surfaces B., Amsterdam, v.51, p.54-61, 2006.

FORMARIZ, T. P.; CHIAVACCI, L. A.; SARMENTO, V. H. V.; SANTILLI, C. V.; TABOSA DO EGITO, E. S. OLIVEIRA, A. G. Relationship between structural features and in vitro release of doxorubicin from biocompatible anionic microemulsion. Colloids Surfaces B., Amsterdam, v.60, p.28-35, 2007.
FORMARIZ, T. P.; WANCZINSKI, B. J.; JÚNIOR-SILVA, A. A.; SCARPA, M. V.; OLIVEIRA, A. G. Biotecnologia de sistemas coloidais aplicável na otimização do efeito terapêutico de fármacos usados no tratamento do câncer. Infarma, Brasília, v.16, p.44-57, 2004.

HADGRAFT, J. Skin, the final frontier. Int. J. Pharm., Amsterdam, v. 224, p.1-18, 2001.

MITTAL, K. L.; LINDMAN, B. (Eds.). Surfactants in solution. Plenun: New York, 1984. 772p.

KUMAR, P.; MITTAL, K. L. (Eds). Handbook of Microemulsion Science and Technology. New York: Marcel Dekker, 1999. 864p.

KREILGAARD, M. Influence of microemulsions on cutaneous drug delivery. Adv. Drug Deliv. Rev., Arlington, v.54, p.77-98, 2002.

LAWRENCE, M. J; REES, D. G. Microemulsions-based as novel drug delivery systems. Adv. Drug Del. Rev., Arlington, v.45, p.89-121, 2000.

MATSUMOTO, S.; SHERMANN, P. The viscosity of microemulsions. J. Colloid Interface Sci., London, v.30, p.525-536, 1969.

MOLLET, H.; GRUBENMANN A. Formulation technology. 5. ed. Berlin: Wiley-VCH, 2001. p.247-259.

NAGARAJAN, R.; RUCKENSTEIN, E. Molecular theory of microemulsions. Langmuir, v.16, p.6400-6415, 2000.

OLIVEIRA, A. G.; SCARPA, M. V. Microemulsões I: fundamentos teóricos da formação do sistema microemulsionado. Infarma, Brasília, v.13, p.73-79, 2001.

OLIVEIRA, A. G.; SCARPA, M. V.; CHAIMOVICH, H. Effect of hexadecyltrimethylammonium bromid-based microemulsions on the rate of decomposition of betalactam antibiotic cephaclor. J. Pharm. Sci., Washington, v.86, p.616-620, 1997.

OLIVEIRA, A. G.; SCARPA, M. V.; CORREA, M. A.; CERA, L. F. R.; FORMARIZ, T. P., Estrutura e aplicações de microemulsões como sistema de liberação de fármacos. Quím. Nova, São Paulo, v.27, p.131-138, 2004. 
OLIVEIRA, A. G.; SCARPA, M. V.; FORMARIZ, T. P.; WACZINSKI, B. J., Estabilidade de antibióticos $\beta$ lactâmicos incorporados em micelas microemulsões e outros agregados supramoleculares. Infarma, Brasília, v.15, p.80-84, 2003.

OVERBEEK, J. T. G.; BRUYN, P. L.; VERHOECKY, F. Microemulsions, in surfactants. London: Academic Press, 1984. 342p.
ROSANO, H. L. Microemulsions. J. Soc. Cosmet. Chem., Clermont, v.25, p.609-19, 1974.

WESTER, R. C.; MAIBACH, H. I. Drug delivery on skin vs. application frequency. Cosmetics \& Toiletries, Carol Stream, v.111, p.75-77, 1996.

Recebido para publicação em 18 de janeiro de 2007. Aceito para publicação em 29 de outubro de 2007. 